S U M A R I O

Alberto Sandoval y Frances Aparicio, Introducción ... ... . . . . . . . . . . . . . . ...

\title{
I. Estudios
}

ERLINDA GonZÁLEs-BeRRY, Sobre cruzar fronteras y robar banderas: confesiones

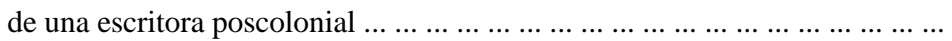

Eliana Rivero, Latinounidenses: identidad, cultura, textos ... ... .............. RAmÓn Figueroa, Fantasmas ultramarinos: la dominicanidad en Julia Alvarez y

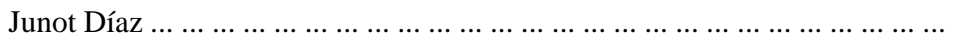

Silvia Spitta, Un altar a la presencia: los objetos hallados, la fotografía, la memoria y la identidad latina en EE.UU. ... ... . . . . . . . . . . . . . . . . . . . . .

Yolanda FloRes, Memory Mambo: un paso hacia adelante, dos pasos hacia atrás

Laura P. Alonso Gallo, Cuerpos de Cuba: alegorías de Cuba a través del cuerpo femenino en la narrativa cubano-americana $\ldots \ldots \ldots \ldots \ldots \ldots \ldots \ldots$

Michelle Joffroy, El espacio relacional/Las relaciones espaciales: la práctica del feminismo chicano en la literatura fronteriza contemporánea ..............

Ellen McCracken, Globalización y ética: la teología de la liberación en las novelas de Graciela Limón y Demetria Martínez ... . . . . . . . . . . . . . . . . . . .

María DeGuzmán, La histórica noche de deseo: recuperando una comunidad

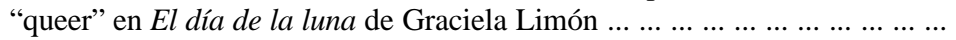

IsRael Reyes, Recuerdos "parciales" y el closet de la literatura: ficción y autobiografía de Judith Ortíz Cofer $\ldots \ldots \ldots \ldots \ldots \ldots \ldots \ldots \ldots \ldots \ldots \ldots \ldots \ldots$

Jossianna Arroyo, Itinerarios de viaje: las otras islas de Manuel Ramos Otero

Lawrence La Fountain-Stokes, Entre boleros, travestismos y migraciones translocales: Manuel Ramos Otero, Jorge Merced yEl bolero fue mi ruina del teatro Pregones del Bronx $\ldots \ldots \ldots \ldots \ldots \ldots \ldots \ldots \ldots \ldots \ldots \ldots \ldots \ldots \ldots \ldots \ldots$

Yvonne Yarbro-Bejarano, Por todos nuestros anhelos: el género y la crianza en la serigrafía chicana (II Taller Maestras de Self Help Graphics 2001) ... ...

703

711

731

745

763

775

801

815

833

847

865

887 


\section{RESEÑAS}

Gloria Prosper-SÁnchez sobre José Del Valle y Luis Gabriel-Stheeman, eds. The Battle over Spanish between 1800 and 2000. Language Ideologies and

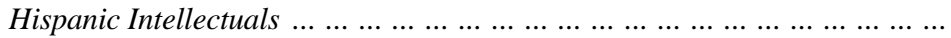
Elena Altuna sobre Julio Schvartzman, director. La lucha de los lenguajes. Volumen 2 de la Historia Crítica de la Literatura Argentina ... ... ............

Lelia Area sobre Abril Trigo. Memorias migrantes. Testimonios y ensayos

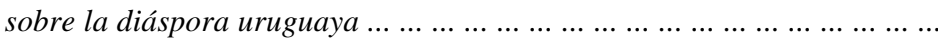

NANCY Vogeley sobre Beatriz Garza Cuarón, Georges Baudot, coord. Historia de la literatura mexicana, Las literaturas amerindias de México y la literatura en español del siglo XVIII 1 y RAQuel CHANG-RodRíguez, coord. Historia de la literatura mexicana, La cultura letrada en la Nueva España del siglo XVIII 2

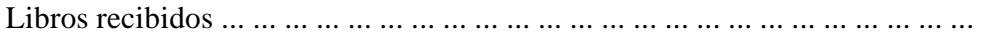

